\title{
The Influence of Organic Groceries Placement Decisions on Retail Store Consumers' Shopping Behavior: An Abstract
}

\author{
Maria Schwabe and Gianfranco Walsh
}

\begin{abstract}
In the past decades, the market for organic products has grown immensely. However, the market shares of organic products remain low. This situation is intriguing because various stakeholders, especially food retailers, can be expected to gain from a greater market share of organic products. Although in-store marketing instruments are considered effective in influencing the behavior of consumers at the point of sale, empirical evidence of the influenceability of consumers while shopping is scarce. The present research aims to investigate the effect of different shelf placements of organic products on key performance indicators of retailers, such as customer shopping basket value, dwell time, and purchase satisfaction. In particular, we compare the prevalent category-based placement of organic products to the clustered placement of organic groceries. Using data from an experimental retail setting, the authors find that placing organic grocery products together encourages shoppers to buy more organic items but also to dwell longer and to spend more money overall. Furthermore, we find that purchase satisfaction decreases when organic groceries are placed together in one separate shelf. The findings extend previous research and have important implications for marketing theory and practice.
\end{abstract}

References Available Upon Request

M. Schwabe $(\bowtie) \cdot$ G. Walsh

Friedrich-Schiller-University of Jena, Jena, Germany

e-mail: maria.schwabe@uni-jena.de; walsh@uni-jena.de 